\title{
Are farmer assessed temperament, milking speed, and leakage genetically the same traits in automatic milking systems and traditional milking systems?
}

\author{
K. B. Wethal, ${ }^{1 *} \odot$ M. Svendsen, ${ }^{2} \odot$ and B. Heringstad ${ }^{1} \odot$ \\ ${ }^{1}$ Department of Animal and Aquacultural Sciences, Faculty of Biosciences, Norwegian University of Life Sciences, PO Box 5003 , \\ 1432 Ås, Norway \\ ${ }^{2}$ GENO Breeding and Al Association, 2326 Hamar, Norway
}

\begin{abstract}
The aim was to investigate whether subjectively scored milking speed, temperament, and leakage are genetically the same trait when measured in different milking systems. Data were provided by the Norwegian Dairy Herd Recording System and included a total of 260,731 first-parity Norwegian Red cows calving between January 2009 and February 2019 and milked either in a traditional milking system (milking parlor or pipeline) or by an automatic milking system (AMS). Genetic parameters were estimated and lower heritabilities and less genetic variation were found for the 3 traits when measured in AMS herds. The heritability of temperament, leakage, and milking speed were $0.05,0.04$, and 0.22 , respectively, with data from AMS herds; and $0.09,0.14$, and 0.27 , respectively, with data from cows milked in traditional milking systems. The genetic correlations between temperament and leakage $(-0.19)$, between milking speed and leakage $(-0.88)$, and between milking speed and temperament (0.30) in AMS were slightly stronger than between the corresponding traits assessed in other milking systems $(-0.15,-0.82$, and 0.16 , respectively). The genetic correlations between traits across milking systems were strong: $0.98,0.96$, and 0.86 for milking speed, leakage, and temperament, respectively. Strong correlations indicate that the traits were almost genetically similar despite being scored in different milking systems. The rank correlations among estimated sire breeding values were strong: 0.98 and 0.99 for milking speed and leakage, with little or no reranking of bull performance across milking systems. Temperament had the lowest genetic correlation (0.86) and rank correlation (0.91) across milking systems. These data suggest that AMS farmers evaluate temperament slightly differently from
\end{abstract}

Received August 27, 2019.

Accepted December 18, 2019.

*Corresponding author: karoline.bakke@nmbu.no farmers using other milking systems or that different aspects of temperament are important for farmers with AMS.

Key words: workability, genetic correlations, automatic milking system (AMS), milking parlor

\section{INTRODUCTION}

Dairy production in Norway is moving toward larger herds with more automatic milking systems (AMS). In 2018, $45 \%$ of Norwegian dairy cows were milked by AMS (Tine, 2019), a proportion expected to increase further. The workability traits temperament, milking speed, and leakage have been included in the selection program for Norwegian Red (NR) since the 1970s. Genetic evaluation of these traits is based on owner assessments of first-parity cows on a 3-point scale, with 1 being favorable and 3 unfavorable. Workability in freestall systems is important, especially because of tightened time budgets in larger herd units.

Subjectively scored workability traits are reported to have heritabilities from 0.05 to 0.35 (Jakobsen et al., 2008). Leakage is not commonly included in routine genetic evaluations. Undesirable dripping of milk from the udder between milkings can transmit udder bacteria between individuals when milk is left in the stall and is associated with a higher risk of mastitis (Persson Waller et al., 2003). Heritability of leakage is estimated to be 0.08 in first-parity Holstein and Ayrshire cows (Luttinen and Juga, 1997) and 0.14 in NR cows (Bakke and Heringstad 2015). An unfavorable genetic correlation between milking speed and leakage of 0.65 was estimated for Finnish dairy cattle (Luttinen and Juga, 1997), and a stronger correlation of -0.84 was estimated for NR by Bakke and Heringstad (2015), where reversed scales for leakage and speed led to a negative value. Heritability of farmer-assessed milking speed ranges from 0.10 to 0.24 in the literature (Luttinen and Juga, 1997; Rensing and Ruten, 2005; Wiggans et al., 2007; Sewalem et al., 2011), whereas larger heritability 
estimates were reported for milking speed measured more exactly; for example, in kilograms of milk per minute (Carlström et al., 2014; Wethal and Heringstad, 2019). Heritability of temperament, phenotypically scored from easy/calm to uneasy/nervous, ranges from 0.05 to 0.21 in various breeds and countries, according to the international genetic evaluations of workability traits reported by Jakobsen et al. (2008). Sewalem et al. (2011) estimated similar heritabilities of temperament ranging from 0.13 to 0.20 . To date, few studies have investigated differences of farmer-assessed traits between milking systems. Whether subjectively scored workability traits are genetically the same trait in AMS as in traditional milking systems (pipeline or milking parlor) is an interesting question. One approach to examine this is to define traits measured in different systems as different traits and estimate correlations between them. A genetic correlation $<1$ would then indicate that farmers do not necessarily measure the same genetic trait when they score workability traits. If so, a revision of the genetic evaluation of the trait may be recommended. A similar approach was used by Lassen and Mark (2008), who estimated a strong genetic correlation between tiestall and freestall for both temperament and milking speed (0.95 and 0.94). We aimed to compare AMS and other milking systems with the following hypotheses. (1) A lower frequency of cows is scored for leakage in AMS; (2) milking speed scored in AMS herds has better quality and variation because farmers have access to extra information on, for example, flowrate; and (3) temperament of AMS cows is not the same trait genetically as temperament in other milking systems because other aspects are favored by farmers. The specific aims of our study were thus to estimate heritability and genetic correlations among workability traits within the same type of milking system and to estimate genetic correlations across milking systems to evaluate whether farmer-assessed temperament, milking speed, and leakage of NR cows are genetically the same traits for different milking systems.

\section{MATERIALS AND METHODS}

\section{Data Material}

The Norwegian dairy herd recording system provided all necessary data for this study. First-parity cows with calving dates from January 2009 to February 2019 were included for genetic analyses. The pedigree was traced back as far as possible, up to 8 generations. All herds had information about barn type (tiestall or freestall) and milking system (pipeline, milking parlor, or AMS) that made it possible to compare traits recorded on cows in different systems.

\section{Traits}

The workability traits milking speed, leakage, and temperament were scored subjectively by the farmer on a scale from 1 to 3 . Milking speed was scored as 1 (fast), 2 (intermediate), or 3 (slow). Temperament was scored as 1 (extra nice), 2 (ordinary), or 3 (bad-tempered/mean). Leakage of milk between milkings was scored with 1 (no), 2 (some), or 3 (obvious) dripping of milk. The traits are routinely scored in first parity, and guidelines suggest that temperament should be scored during milking and all traits be scored $30 \mathrm{~d}$ after calving. Each trait had a fourth category of "unknown," but this class did not enter the genetic analyses. We defined farmer-assessed workability traits in herds with AMS and in herds with "traditional" milking systems (milking parlor or pipeline) as different traits, which gave 6 traits in total.

\section{Data Edits}

To ensure only reasonable records were included in the genetic analyses, we applied the following restrictions to the data set. Each cow had a known NR AI sire, scoring of each trait was performed between d 30 and 320 after first calving, and age at calving was between 21 and 32 mo. Further, we restricted the data set to include only herds with at least 15 cows evaluated for the traits over a 5-yr period. The final data set contained 260,731 cows in total, with an assessment of workability either in AMS or in other milking systems. Descriptive statistics and number of cows included in the analysis for each trait are given in Table 1.

\section{Statistical Method and Models}

The (co)variance components were estimated for the 6 workability traits: temperament, milking speed, and leakage in AMS and in other milking systems. Genetic correlations within and between milking systems were estimated. The DMUAI package, for average information-REML (AI-REML), in the DMU software by Madsen and Jensen (2013) was used. Fixed effects were included in the model if the effect was significant with $P<0.01$ in analyses by GLM procedure in SAS (version 9.4; SAS Inst. Inc., Cary, NC).

Models. Bivariate models were used to estimate the (co) variance components, as follows: 


$$
\left[\begin{array}{l}
\mathbf{y}_{1} \\
\mathbf{y}_{2}
\end{array}\right]=\left[\begin{array}{cc}
\mathbf{X}_{1} & 0 \\
0 & \mathbf{X}_{2}
\end{array}\right]\left[\begin{array}{l}
\mathbf{b}_{1} \\
\mathbf{b}_{2}
\end{array}\right]+\left[\begin{array}{cc}
\mathbf{Z}_{1} & 0 \\
0 & \mathbf{Z}_{2}
\end{array}\right]\left[\begin{array}{l}
\mathbf{a}_{1} \\
\mathbf{a}_{2}
\end{array}\right]+\left[\begin{array}{l}
\mathbf{e}_{1} \\
\mathbf{e}_{2}
\end{array}\right]
$$

where $\mathbf{y}_{1}$ and $\mathbf{y}_{2}$ are vectors of observations of 2 traits: milking speed, temperament, or leakage in either AMS or other milking systems. The incidence matrices $\mathbf{X}_{1}$ and $\mathbf{X}_{2}$ relate each observation to the fixed effects in $\mathbf{b}_{1}$ and $\mathbf{b}_{2}$, respectively; $\mathbf{Z}_{1}$ and $\mathbf{Z}_{2}$ are incidence matrices relating the random additive genetic effects of animal in $\mathbf{a}_{1}$ and $\mathbf{a}_{2}$ to each observation; $\mathbf{e}_{1}$ and $\mathbf{e}_{2}$ are the random residual effects for the 2 traits. For the additive genetic effect of animal (a), the following assumptions were made:

$$
\left[\begin{array}{l}
\mathbf{a}_{1} \\
\mathbf{a}_{2}
\end{array}\right] \sim N\left(\left[\begin{array}{l}
0 \\
0
\end{array}\right], \mathbf{A} \otimes\left[\begin{array}{cc}
\sigma_{a_{1}}^{2} & \sigma_{a_{1} a_{2}} \\
\sigma_{a_{1} a_{2}} & \sigma_{a_{2}}^{2}
\end{array}\right]\right),
$$

where $\mathbf{a}_{1}$ and $\mathbf{a}_{2}$ are additive genetic effects of animal for the 2 traits, assumed to be normally distributed, with expectation 0 ; and $\mathbf{A}$ is the additive relationship matrix containing 805,008 animals. The Kronecker product is denoted by $\otimes ; \sigma_{a_{1}}^{2}$ and $\sigma_{a_{2}}^{2}$ denote the additive genetic variances for the 2 traits and $\sigma_{a_{1} a_{2}}$ the additive genetic covariance between the traits. The following assumptions were made about the residual effects assigned 2 traits within milking systems:

$$
\left[\begin{array}{l}
\mathbf{e}_{1} \\
\mathbf{e}_{2}
\end{array}\right] \sim N\left(\left[\begin{array}{l}
0 \\
0
\end{array}\right], \mathbf{I} \otimes\left[\begin{array}{cc}
\sigma_{e_{1}}^{2} & \sigma_{e_{1} e_{2}} \\
\sigma_{e_{1} e_{2}} & \sigma_{e_{2}}^{2}
\end{array}\right]\right),
$$

where $\mathbf{e}_{1}$ and $\mathbf{e}_{2}$ were normally distributed with expectation $0, \mathbf{I}$ was an identity matrix, $\sigma_{e_{1}}^{2}$ and $\sigma_{e_{2}}^{2}$ are the residual variances for the 2 traits, and $\sigma_{e_{1} e_{2}}$ is the residual covariance between the traits. To estimate genetic correlations between the same workability trait across milking systems, the following assumptions were made about the residuals in the model:

$$
\left[\begin{array}{l}
\mathbf{e}_{1} \\
\mathbf{e}_{2}
\end{array}\right] \sim N\left(\left[\begin{array}{l}
0 \\
0
\end{array}\right], \mathbf{I} \otimes\left[\begin{array}{cc}
\sigma_{e_{1}}^{2} & 0 \\
0 & \sigma_{e_{2}}^{2}
\end{array}\right]\right),
$$

where no covariance existed between the residuals; therefore, $\sigma_{e_{1} e_{2}}$ was restricted to zero for traits assessed in different milking systems.

Fixed Effects. The following fixed effects were included in the models for milking speed, leakage, and temperament: calving year and month, with 121 levels from January 2009 to February 2019; age at first calving, with 12 classes from 21 to 32 mo; and DIM grouped in 12 periods of $\sim 25 \mathrm{~d}$ each. Finally, the fixed effect of herd $\times$ year, grouped in 5 -yr periods due to small subclasses of animals, was included. The total number of levels for herd by 5-yr periods were 1,548 and 6,326 in AMS and other milking systems, respectively. Additionally, type of milking system was included as a fixed effect in model when workability in other milking systems was analyzed, because of 2 possibilities (parlor or pipeline).

Heritability and Genetic Correlations. Heritability $\left(h^{2}\right)$ was calculated as follows:

$$
h^{2}=\frac{\sigma_{a}^{2}}{\sigma_{a}^{2}+\sigma_{e}^{2}},
$$

where $\sigma_{a}^{2}$ is the additive animal genetic variance and $\sigma_{e}^{2}$ is the residual variance.

Genetic correlations $\left(r_{g}\right)$ were estimated by

$$
r_{g}=\frac{\sigma_{a_{1} a_{2}}}{\sqrt{\sigma_{a_{1}}^{2}, \sigma_{a_{2}}^{2}}}
$$

where $\sigma_{a_{1} a_{2}}$ is the additive genetic covariance between the 2 traits, and $\sigma_{a_{1}}^{2}$ and $\sigma_{a_{2}}^{2}$ are the additive genetic variance estimated for the respective traits.

Table 1. Descriptive statistics of first-parity cows with subjective scores for temperament, leakage, and milking speed in AMS and other milking systems

\begin{tabular}{llcccr}
\hline System $^{1}$ & Trait & & & \multicolumn{2}{c}{$\begin{array}{c}\text { No. of cows } \\
\text { unknown }\end{array}$} \\
\hline AMS & Temperament & No. of cows & Mean & SD & 48 \\
& Milking speed & 72,683 & 1.90 & 0.46 & 244 \\
\multirow{2}{*}{ Other } & Leakage & 72,487 & 1.96 & 0.64 & 5,988 \\
& Temperament & 66,743 & 1.16 & 0.42 & 21 \\
& Milking speed & 187,979 & 1.90 & 0.53 & 103 \\
& Leakage & 187,897 & 1.91 & 0.56 & 489 \\
\hline
\end{tabular}

${ }^{1} \mathrm{AMS}=$ automatic milking systems; other $=$ milking parlor and pipeline milking systems.

${ }^{2}$ Temperament: $1=$ extra nice, $2=$ ordinary, or $3=$ bad. Milking speed: $1=$ fast, $2=$ intermediate, or $3=$ slow. Leakage: $1=$ no, $2=$ some, or $3=$ obvious. 


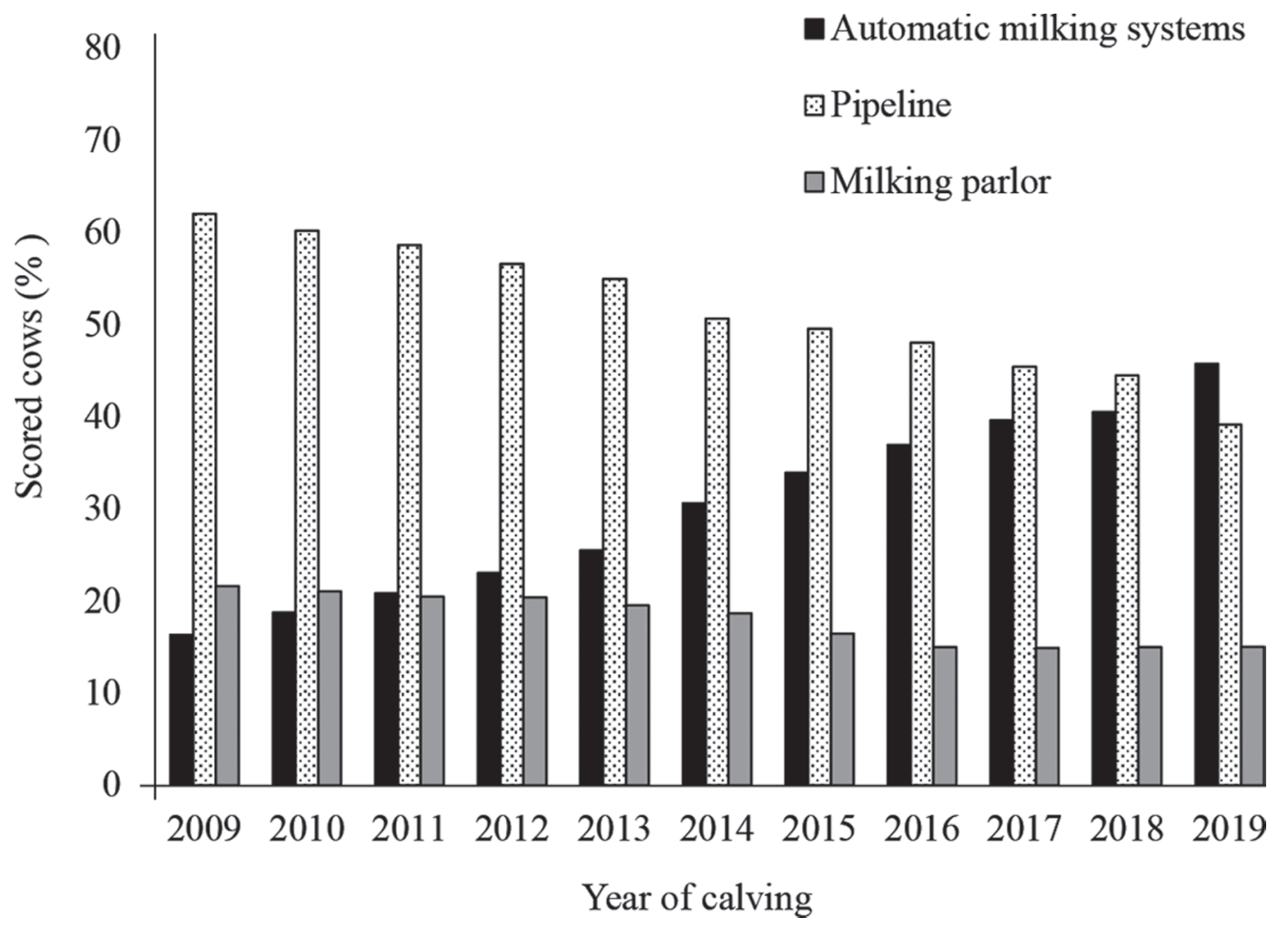

Figure 1. Percentage of Norwegian Red first-parity cows assessed by farmers for workability (milking speed, temperament, and leakage) in different types of milking systems from January 2009 to February 2019.

Rank Correlations of Sire $\boldsymbol{E} B \boldsymbol{V}$. As a measure of reranking among bulls, Spearman correlations between EBV of NR sires with at least 20 daughters in each milking system were estimated by using Proc Spearman in SAS (version 9.4; SAS Inst. Inc.).

\section{RESULTS}

\section{Distributions Within Traits}

Proportions of cows scored for workability traits since 2009 are shown in Figure 1; almost $50 \%$ of farmer-assessed first-parity cows were milked in AMS by February 2019. The percentage of first-parity cows scored for temperament, leakage, and milking speed in different milking systems are shown in Figures 2, 3, and 4 , respectively. The distribution of cows over classes of temperament were similar in the 3 milking systems (Figure 2), although pipeline systems tended to have higher proportions of cows in the extreme classes (extra nice or bad), and AMS showed the largest proportion of cows scored as ordinary. All 3 milking systems had a low proportion of unclassified animals (unknown).

For leakage, a much larger proportion of cows in AMS, $9 \%$, were not scored compared with $<1 \%$ in the other systems. The AMS group also showed the lowest proportion of cows scored with some and obvious leakage (Figure 3). For milking speed (Figure 4), the largest difference between AMS and other milking systems were for the categories intermediate and slow: AMS

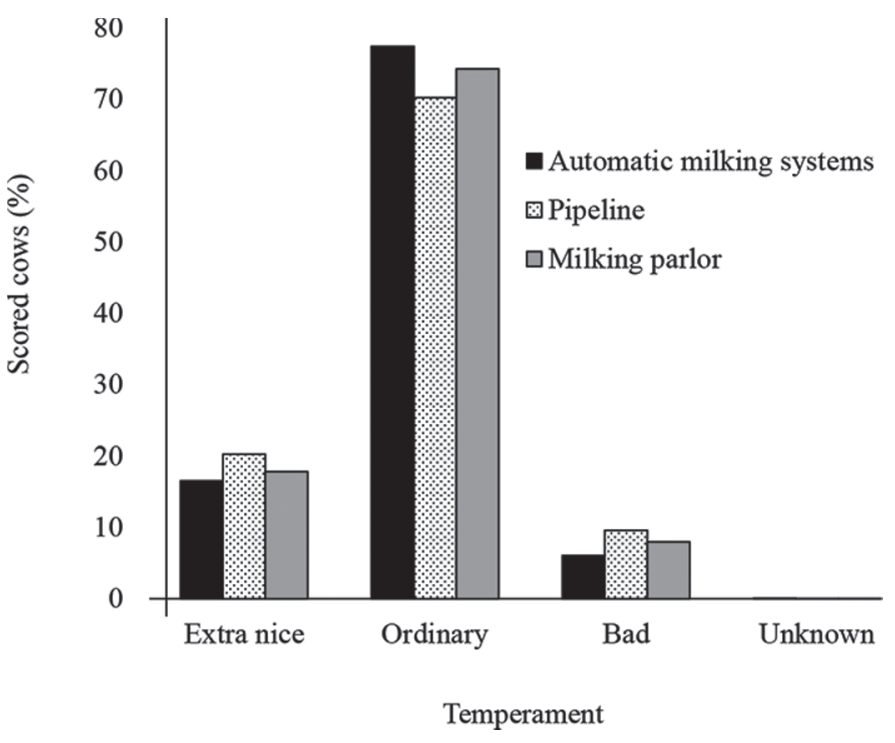

Figure 2. Farmer-scored temperament of first-parity Norwegian Red cows. 
Table 2. Estimated additive genetic variance $\left(\sigma_{a}^{2}\right)$, residual variance $\left(\sigma_{e}^{2}\right)$, and heritability $\left(h^{2}\right)$ ( $\mathrm{SE}$ in parentheses) of subjectively assessed traits in AMS and other milking systems

\begin{tabular}{llccc}
\hline System $^{1}$ & $\begin{array}{l}\text { Variance } \\
\text { component }\end{array}$ & Milking speed & Leakage & Temperament \\
\hline AMS & $\sigma_{a}^{2}$ & $0.09(0.005)$ & $0.005(0.001)$ & $0.01(0.001)$ \\
& $\sigma_{e}^{2}$ & $0.31(0.004)$ & $0.13(0.001)$ & $0.18(0.001)$ \\
\multirow{2}{*}{ Other } & $h^{2}$ & $0.22(0.01)$ & $0.04(0.004)$ & $0.05(0.006)$ \\
& $\sigma_{a}^{2}$ & $0.08(0.002)$ & $0.03(0.001)$ & $0.02(0.001)$ \\
& $\sigma_{e}^{2}$ & $0.22(0.002)$ & $0.19(0.001)$ & $0.21(0.001)$ \\
& $h^{2}$ & $0.27(0.007)$ & $0.14(0.006)$ & $0.09(0.006)$ \\
\hline
\end{tabular}

${ }^{1} \mathrm{AMS}=$ automatic milking systems; other = milking parlor and pipeline milking systems.

showed the largest proportion of cows with slow milking and fewer cows with intermediate milking speed.

\section{Heritability}

Variance components for all traits measured in both AMS and other milking systems were significantly different from zero and had low standard errors on estimates (Table 2). Heritabilities varied from 0.04 to 0.27 , and all traits had lower heritability in AMS. The largest difference was in leakage, where heritability was 0.04 in AMS and 0.14 in other systems.

\section{Genetic Correlations Within Milking System}

Estimated genetic correlations between milking speed, temperament, and leakage of cows within the same milking system are shown in Table 3; correla-

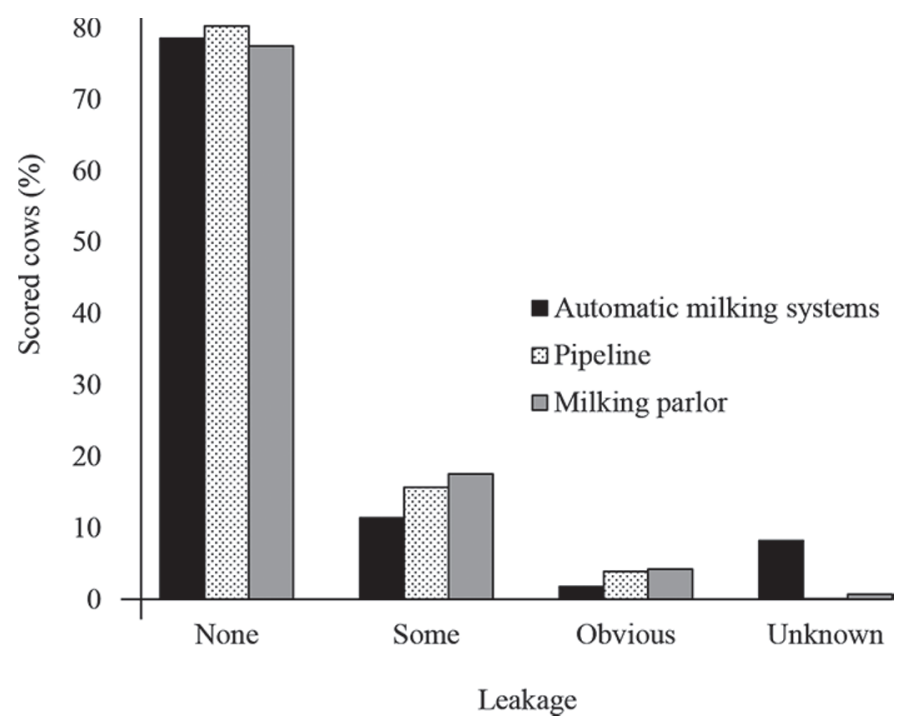

Figure 3. Farmer-scored milk leakage of first-parity Norwegian Red cows in different milking systems. tions were slightly higher in AMS for all combinations of traits and estimates were larger than standard errors. The genetic correlations showed absolute values ranging from 0.15 to 0.88 . The strongest genetic correlation was found between leakage and milking speed in AMS, an unfavorable correlation of -0.88 resulting in increased leakage with higher milking speed. The correlations of temperament with milking speed and leakage were weak.

\section{Distribution of Breeding Values for Bulls}

Figure 5 show the distribution of EBV of NR sires for temperament in different milking systems. The frequency of bulls with EBV around the population mean was higher for traits in AMS, except for milking speed, which showed greater variation in EBV for AMS. The range of EBV for each trait in the different milking systems can be seen in Table 4 .

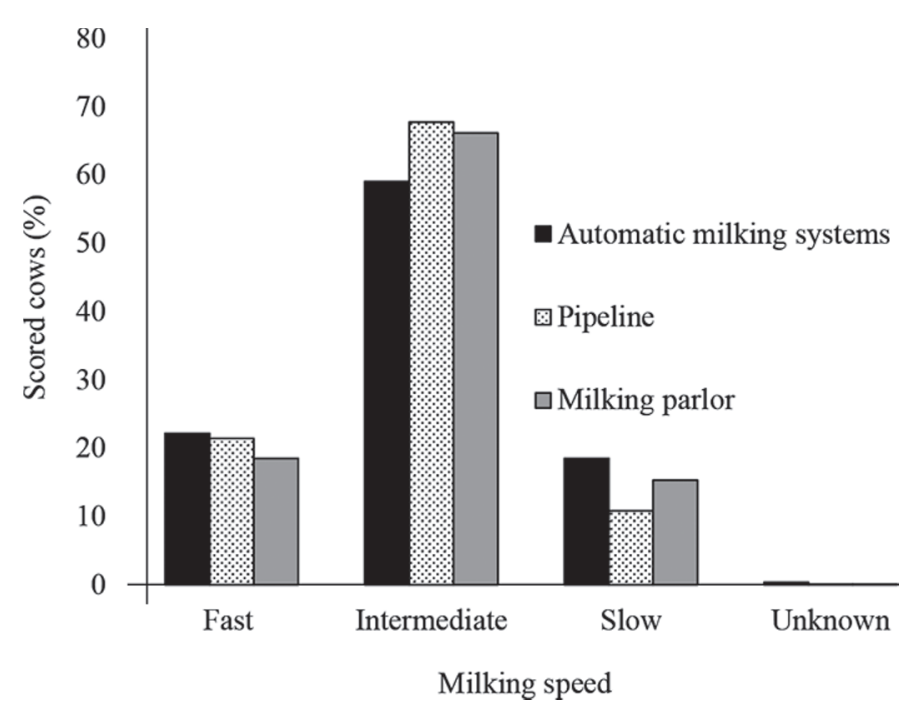

Figure 4. Farmer-scored milking speed of first-parity Norwegian Red cows milked in different milking systems. 
Table 3. Estimated genetic correlations (SE in parentheses) between milking speed, temperament, and leakage within milking system ${ }^{1}$

\begin{tabular}{lrr}
\hline Trait & \multicolumn{1}{c}{ AMS } & \multicolumn{1}{c}{ Other } \\
\hline Milking speed - Temperament & $0.30(0.06)$ & $0.16(0.03)$ \\
Milking speed - Leakage & $-0.88(0.03)$ & $-0.82(0.01)$ \\
Temperament - Leakage & $-0.19(0.11)$ & $-0.15(0.04)$ \\
\hline
\end{tabular}

${ }^{1} \mathrm{AMS}=$ automatic milking systems; other = milking parlor and pipeline milking systems.

\section{Rank Correlations Between Bull EBV}

Rank correlations between bull EBV in different milking systems are shown in Table 4. The strong Spearman correlations implied a low degree of reranking among bulls. Temperament showed some reranking among bulls despite strong correlations. Results showed that 6 out of 10 bulls were among the top 10 for both systems. For milking speed, 9 out of 10 bulls were among the top 10 in both systems.

\section{Genetic Correlations Within Trait Across Milking Systems}

The genetic correlations between the same traits measured in the 2 milking system groups are in Table
4. All genetic correlations were strong and ranged from 0.86 to 0.98 , indicating that the traits were the same genetically. The weakest genetic correlation was for temperament in AMS and other milking systems.

\section{DISCUSSION}

\section{Genetic Parameters of Workability}

The heritabilities estimated for traits assessed in AMS were lower than for the corresponding traits in traditional milking systems. Estimates for temperament and leakage were much lower in AMS, whereas the difference was relatively small for milking speed. No other study has compared genetic parameters of workability in AMS with other milking systems. However, heritability estimates from both milking systems were within the range of heritability reported in previous studies estimating genetic parameters of farmer-assessed milking speed and temperament (Cue et al., 1996; Wiggans et al., 2007; Jakobsen et al., 2008; Sewalem et al., 2011). Milking speed assessed by farmers was reported to have the largest heritability among the workability traits (0.10 to 0.24; Luttinen and Juga, 1997; Rensing and Ruten, 2005; Wiggans et al., 2007; Sewalem et al.,

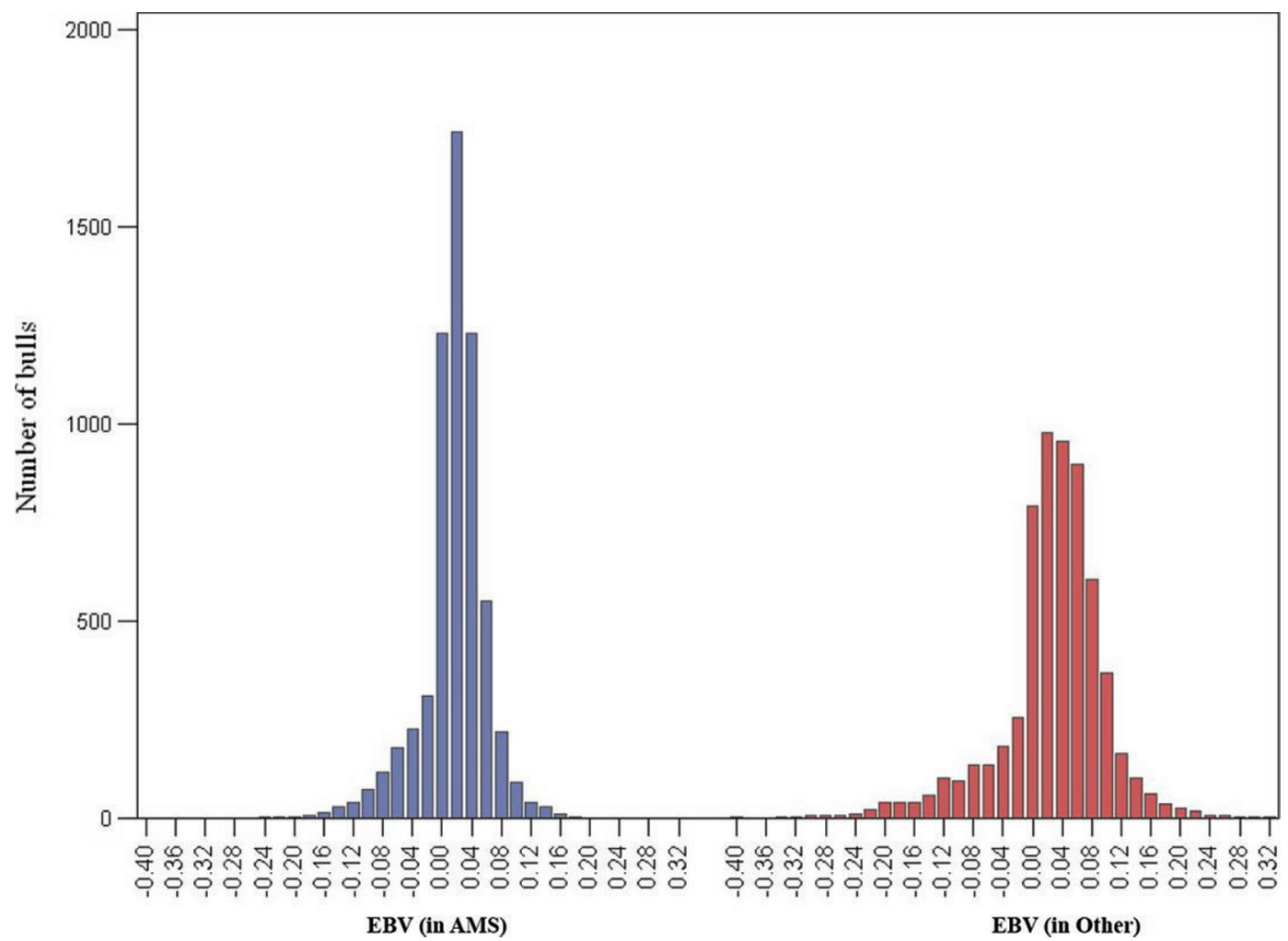

Figure 5. Distribution of EBV of Norwegian Red AI bulls for temperament in automatic milking systems (AMS) and other systems (parlor and pipeline). 
Table 4. Estimated genetic correlations (SE in parentheses) between milking speed, temperament, and leakage in AMS and other milking systems ${ }^{1}$

\begin{tabular}{lccc}
\hline Item & Milking speed & Leakage & Temperament \\
\hline Genetic correlation & $0.98(0.01)$ & $0.96(0.02)$ & $0.86(0.03)$ \\
Rank correlation bull EBV ${ }^{2}$ & $0.99(<0.01)$ & $0.98(<0.01)$ & $0.91(<0.01)$ \\
EBV range ${ }^{2}$ for AMS & -0.71 to 0.92 & -0.14 to 0.22 & -0.23 to 0.16 \\
EBV range for other & -0.62 to 0.86 & -0.35 to 0.56 & -0.40 to 0.26 \\
${ }^{1}$ AMS = automatic milking systems; other = milking parlor and pipeline milking systems. \\
${ }^{2}$ Spearman correlations among bull EBV (SD) and range of EBV for 704 Norwegian Red AI bulls with $\geq 20$ \\
assessed daughters in each system.
\end{tabular}

2011). Greater heritability was reported when classifiers evaluated milking speed (Lassen and Mark, 2008). Heritability of farmer-assessed milking speed for Nordic Red cattle is reported to be 0.25 (Jakobsen et al., 2008), similar to current results. Heritability for average milk flow rate ranged from 0.27 to 0.38 in Swedish Red and Swedish Holstein when milked in parlors (Carlström et al., 2014). For milking speed measured in AMS, higher heritability estimates have been reported, ranging from 0.37 to 0.48 (Carlström et al., 2013; Wethal and Heringstad, 2019).

The heritability of leakage measured in traditional milking systems was higher (0.14) in this study than previous estimates. Luttinen and Juga (1997) studied leakage in Finnish Holstein and Ayrshire cows and estimated a heritability of 0.08 when measured as a binary trait. The frequency of cows with leakage $(9 \%)$ was lower in the study by Luttinen and Juga (1997) than observed in the current study. Our estimated heritability for leakage (0.04) in AMS was much lower than in traditional milking systems. In AMS, a larger proportion of animals had unknown leakage ( $9 \%$ vs. $<1 \%$ ) and thus fewer cows were scored.

Previous studies have reported heritability estimates of temperament ranging from 0.05 to 0.25 (Visscher and Goddard, 1995; Rensing and Ruten, 2005; Jakobsen et al., 2008; Lassen and Mark, 2008). Our heritability estimate of temperament of NR in traditional milking systems was in agreement with the value of 0.10 reported by Bakke and Heringstad (2015). The heritability of 0.128 estimated for Canadian Holsteins (Sewalem et al., 2011) was also comparable to our results in traditional milking systems. The heritability estimate for temperament was lower in AMS than in other milking systems (0.05 vs. 0.09). Lassen and Mark (2008) compared tiestall and freestall systems and estimated lower genetic variation for temperament in the freestall systems, with estimates of 0.17 and 0.22 , respectively. They suggested that errors in cow identification or pedigree explain the lower additive genetic variance in freestall systems, and that these farmers had more difficulty in scoring animals correctly. In our study, each category of the scale for temperament and leakage was used to a lower extent in AMS than in other systems (Figures 2 and 3), causing lower phenotypic variance.

\section{Genetic Correlations Between Milking Systems}

The strong genetic correlations $(\geq 0.86)$ between milking systems indicated that milking speed, temperament, and leakage are the same traits genetically in AMS as in traditional milking systems. To the best of our knowledge, this study is unique in comparing farmerassessed workability traits in AMS with other milking systems genetically. However, Lassen and Mark (2008) compared tiestall and freestalls and estimated strong genetic correlations between barn types for milking speed and temperament of 0.94 and 0.95 , respectively. Our results showed even stronger correlations between milking speed than did Lassen and Mark (2008). Although not directly comparable to our study, Mulder et al. (2004) reported strong genetic correlations (0.79-1) for yield and SCS between milking systems, with lower heritabilities for all traits in AMS. After the AMS was installed, residual variances were reported to increase for yield and SCS (Mulder et al., 2004). In the current study, a large proportion of farms did not change milking systems. An alternative approach to determine how assessments change after introduction of AMS would be to compare workability traits on the same farms before and after AMS installation.

\section{Relationship Between Workability Traits}

We found slightly stronger genetic correlation estimates among traits assessed in AMS. The strongest genetic correlation was, as expected from previous studies, between milking speed and leakage. The genetic relationship between these 2 workability traits is rarely investigated but our results were in line with those of Luttinen and Juga (1997). The strong unfavorable genetic correlation implies that selection for faster milking speed without considering milk leakage would genetically increase the frequency of cows with leakage in the population. In this study, the genetic correlation between milking speed and temperament in AMS 
was twice that in other systems $(0.30$ vs. 0.16$)$. The correlation was positive, indicating that faster milking speed is correlated with better temperament. Similar results were found by Sewalem et al. (2011) and Bakke and Heringstad (2015). Even though the genetic correlation between temperament and milking speed was relatively low, it suggests that selecting for cows with better temperament will increase milking speed and vice versa. The unfavorable correlation between leakage and temperament was weak with a large standard error, especially in AMS.

\section{Interpretation and Practical Use of the Results}

Reasons for decreased heritability when workability was assessed in AMS may include the larger herd size and less direct contact with individual cows. In Norway, AMS herds are larger than average, which results in a lower time budget per animal and might make it challenging to assess individual characteristics. Individual cows may appear anonymous to farmers and therefore scored as average. One of our hypotheses was that other aspects of temperament are favored by farmers in AMS. We found a strong genetic correlation for temperament between AMS and other systems suggesting that similar aspects of temperament are important in all milking systems. However, a correlation of 0.86 suggests some different demands regarding cows' behavior in AMS. Such demands might be related to being milked without human contact and that cows must be self-motivated to visit the AMS. Cows scored with better temperament in AMS may be favored for being more active but also calm when they are milked. In tiestalls, cows are judged based on their behavior during milking.

Differences for milking speed were smaller between milking systems. We hypothesized that more precise recording of milking speed would occur in AMS herds, but this was not reflected in the heritability estimate. An explanation for more successful subjectively scoring of milking speed, compared with leakage, in AMS is the possibility to use registrations about average flow rate $(\mathrm{kg} / \mathrm{min})$ as additional information.

Another hypothesis was that leakage is more difficult to detect in AMS herds. This was partly confirmed. A lower frequency of leakage was observed and a higher proportion of cows were scored as "unknown" in AMS herds, but the strong genetic correlation across systems indicates that farmers are observing the same traits genetically. Despite this, leakage recorded in AMS herds suffered from the lower proportion of cows scored, low prevalence, and thereby lower heritability. Considering that greater milk pressure in the milk alveoli results in a higher likelihood of milk leakage, the best time for recording leakage is probably just before milking. In
AMS herds, it becomes challenging to observe each cow before they are milked. Also, frequent milkings in the robot, with an average milking frequency around 2.45 to 2.63 milkings per day for Red cattle (Carlström et al., 2013; Wethal and Heringstad, 2019), are likely to reduce amount of leakage between milkings because of lower milk pressure in the udder. We found few cows were recorded with obvious dripping of milk: $2 \%$ in AMS and $4 \%$ in other systems. This is in contrast to Persson Waller et al. (2003), who observed a larger proportion of cows with leakage in AMS compared with a parlor system. It will be important to consider alternative ways to record leakage in AMS herds in the future. An objective alternative way is currently lacking, whereas for temperament, alternative phenotypes can be used for genetic evaluations.

Objective recording in AMS can substitute farmerassessed temperament, and a few studies have confirmed genetic variability of such traits. Automatically recorded kick-offs, connection time, and number of teat cup attachments in AMS are examples of objective records describing temperament, and they generally have higher heritability than the traditional subjectively scored temperament (Carlström et al., 2016; Stephansen et al., 2018; Wethal and Heringstad, 2019). Stephansen et al. (2018) also analyzed average connection time and number of attachments per teat in AMS as measurements of cows' milking temperament. The estimated heritability was 0.36 for connection time and 0.26 for number of attachments, and correlations with farmer-assessed temperament were -0.29 and -0.37 , respectively, indicating that calmer temperaments are associated with shorter connection times and fewer attachments.

In the future, data from AMS may provide alternative sources of information for genetic evaluations of NR dairy cattle. A functional cow suited for automatic milking will become more important in the future as herd size continues to increase, and workability traits are an important contribution to the perfect "robot cow." Even though leakage in AMS had relatively low heritability, the large correlation with that in other milking systems provides information for genetic evaluation. It should be possible to develop new ways of measuring leakage of cows in freestalls, even though this might be costly. Further investigation of objective ways of recording temperament is recommended. Phenotypic records on subjectively assessed milking speed have alternatives already available, such as flow rate in AMS. The genetic correlations estimated for similar workability traits measured in different milking systems were high in the current study, which indicates that redefinition of today's traits is not necessary and that there is no genotype $x$ environment interaction 
between milking systems. Despite strong genetic correlations across milking systems, a multitrait model might be beneficial for temperament because of heterogeneous variances for different milking systems. Our results indicate that we do not need a new breeding goal for workability traits of AMS cows.

\section{CONCLUSIONS}

Heritability estimates were lower when milking speed, temperament, and leakage were assessed in AMS herds than in other milking systems. Strong and unfavorable genetic correlations between milking speed and leakage were estimated, and genetic correlations between the 3 workability traits were stronger when assessed in AMS than in other systems. The genetic correlations between the same trait measured in different milking systems were strong $(>0.85)$, and the rank correlations between EBV of bulls with daughters in both systems were even stronger $(>0.90)$. This confirms that workability traits are genetically similar in AMS and in traditional milking systems. Lower heritability for leakage and temperament in AMS is one aspect to consider in future genetic evaluations of workability traits, when the majority of Norwegian dairy farms will have AMS.

\section{ACKNOWLEDGMENTS}

The authors acknowledge the Norwegian Dairy Herd Recording System (Ås, Norway) and Geno Breeding and AI association (Hamar, Norway) for providing data for this study. The authors also thank the funding partners of the AMS (project no. 4206000072), and the Norwegian University of Life Sciences (Ås, Norway). The authors have not stated any conflicts of interest.

\section{REFERENCES}

Bakke, K. A., and B. Heringstad. 2015. Data from automatic milking systems used in genetic evaluations of temperament and milkability. Page 287 in Proc. 66th Annu. Mtg. Eur. Assoc. Anim. Prod., Warsaw, Poland. Wageningen Academic Publishers, Wageningen, the Netherlands.

Carlström, C., G. Pettersson, K. Johansson, E. Strandberg, H. Stålhammar, and J. Philipsson. 2013. Feasibility of using automatic milking system data from commercial herds for genetic analysis of milkability. J. Dairy Sci. 96:5324-5332. https://doi.org/10.3168/ jds.2012-6221.

Carlström, C., E. Strandberg, K. Johansson, G. Pettersson, H. Stålhammar, and J. Philipsson. 2014. Genetic evaluation of in-line recorded milkability from milking parlors and automatic milking systems. J. Dairy Sci. 97:497-506. https://doi.org/10.3168/jds .2013-6948.

Carlström, C., E. Strandberg, G. Pettersson, K. Johansson, H. Stålhammar, and J. Philipsson. 2016. Genetic associations of teat cup attachment failures, incomplete milkings, and handling time in automatic milking systems with milkability, temperament, and udder conformation. Acta Agric. Scand. A Anim. Sci. 66:75-83. https:// doi.org/10.1080/09064702.2016.1260153.

Cue, R. I., B. L. Harris, and J. M. Rendel. 1996. Genetic parameters for traits other than production in purebred and crossbred New Zealand dairy cattle. Livest. Prod. Sci. 45:123-135. https://doi .org/10.1016/0301-6226(96)00009-7.

Jakobsen, J. H., V. Palucci, and H. Jorjani. 2008. Feasibility of international genetic evaluation for workability traits. Interbull Bull. 38:101-104.

Lassen, J., and T. Mark. 2008. Short communication: Genotype by housing interaction for conformation and workability traits in Danish Holsteins. J. Dairy Sci. 91:4424-4428. https://doi.org/10 $.3168 /$ jds.2008-1116.

Luttinen, A., and J. Juga. 1997. Genetic relationships between milk yield, somatic cell count, mastitis, milkability and leakage in finnish dairy cattle population. Interbull Bull. 15:78-83.

Madsen, P., and J. Jensen. 2013. A user's guide to DMU. A package for analysing multivariate mixed models. Version 6 , release 5.2. Faculty of Agricultural Sciences (DJF), Department of Genetics and Biotechnology, University of Aarhus, Tjele, Denmark.

Mulder, H. A., A. F. Groen, G. De Jong, and P. Bijma. 2004. Genotype $\times$ environment interaction for yield and somatic cell score with automatic and conventional milking systems. J. Dairy Sci. 87:1487-1495. https://doi.org/10.3168/jds.S0022-0302(04)73300 -7 .

Persson Waller, K., T. Westermark, T. Ekman, and K. SvennerstenSjaunja. 2003. Milk leakage - An increased risk in automatic milking systems. J. Dairy Sci. 86:3488-3497. https://doi.org/10.3168/ jds.S0022-0302(03)73953-8.

Rensing, S., and W. Ruten. 2005. Genetic evaluation for milking speed in German Holstein population using different traits in a multiple trait repeatability model. Interbull Bull. 33:163-166.

Sewalem, A., F. Miglior, and G. J. Kistemaker. 2011. Short communication: Genetic parameters of milking temperament and milking speed in Canadian Holsteins. J. Dairy Sci. 94:512-516. https://doi .org/10.3168/jds.2010-3479.

Stephansen, R. S., A. Fogh, and E. Norberg. 2018. Genetic parameters for handling and milking temperament in Danish first-parity Holstein cows. J. Dairy Sci. 101:11033-11039. https://doi.org/10 $.3168 /$ jds.2018-14804.

Tine. 2019. Statistikksamling fra Ku- og Geitekontrollen 2018. Accessed July 2, 2019. https://medlem.tine.no/aktuelt/nyheter/hk -statistikker/_attachment/476965?_ts=169bdf74e93. [In Norwegian; tables in English]

Visscher, P. M., and M. E. Goddard. 1995. Genetic parameters for milk yield, survival, workability, and type traits for Australian dairy cattle. J. Dairy Sci. 78:205-220. https://doi.org/10.3168/jds .S0022-0302(95)76630-9.

Wethal, K. B., and B. Heringstad. 2019. Genetic analyses of novel temperament and milkability traits in Norwegian Red cattle based on data from automatic milking systems. J. Dairy Sci. 102:8221-8233. https://doi.org/10.3168/jds.2019-16625.

Wiggans, G. R., L. L. M. Thornton, R. R. Neitzel, and N. Gengler. 2007. Short communication: Genetic evaluation of milking speed for Brown Swiss dairy cattle in the United States. J. Dairy Sci. 90:1021-1023. https://doi.org/10.3168/jds.S0022-0302(07)71587 -4 .

\section{ORCIDS}

K. B. Wethal @ https://orcid.org/0000-0002-1268-0854 M. Svendsen ๑ https://orcid.org/0000-0002-2589-0017 B. Heringstad ๑ https://orcid.org/0000-0001-7388-3893 